\title{
APROKSIMASI PADÉ DAN PENERAPANNYA PADA ANALISIS PERFORMANSI DETEKSI RADAR
}

\author{
Deni Saepudin ${ }^{1}$, Kuntjoro Adji Sidarto ${ }^{2}$ \\ ${ }^{1}$ PPDU Sekolah Tinggi Teknologi Telkom, Bandung \\ ${ }^{2}$ Departemen Matematika, Institut Teknologi Bandung \\ 1' $\underline{\text { dns @ stttelkom.ac.id }},{ }^{2}$ sidarto@dns.math.itb.ac.id
}

\begin{abstract}
Abstrak
Aproksimasi Padé adalah suatu teknik aproksimasi dengan menggunakan fungsi rasional. Dalam beberapa hal, teknik ini memberikan hasil yang lebih baik dibandingkan dengan teknik aproksimasi dengan menggunakan polinom Taylor yang biasanya lebih dikenal. Dalam paper ini, aproksimasi Padé digunakan untuk mengaproksimasi fungsi pembangkit momen dari suatu fungsi densitas di sekitar titik asal. Dengan menggunakan invers transformasi Laplace, aproksimasi fungsi densitas dapat diperoleh dan biasanya cukup baik untuk $x$ yang cukup besar. Teknik aproksimasi ini diterapkan untuk menghitung threshold dan peluang deteksi pada deteksi radar bila nilai peluang false alarm diberikan.
\end{abstract}

Kata kunci: aproksimasi Padé, fungsi pembangkit momen, peluang false alarm, peluang deteksi

\section{Abstract}

Padé approximation is an approximation technique using rational functions. In some aspects, this technique gives better results than Taylor polynomial approximation which is more familiar. In this paper, Padé approximation is being used to approximate moment generating function of a probability density function near the origin. Using invers of Laplace transform, the approximate density function can be obtained and usually good enough for large $x$. This approximation technique is applied to compute threshold and detection probability in radar detection performance analysis if the false alarm probability is given.

Keywords: Padé approximation, moment generating function, false alarm probability, detection probability

\section{Pendahuluan}

Sedikitnya ada dua masalah yang memotivasi pembahasan teknik aproksimasi Padé pada tulisan ini. Pertama, hasil aproksimasi Padé yang cukup baik dan bentuknya cukup mudah dalam komputasi. Kedua, untuk memperoleh cara penghitungan threshold dan peluang deteksi yang lebih mudah dalam analisis performansi deteksi radar.

Dalam analisis deteksi radar, salah satu masalah utama yang harus dipecahkan adalah memutuskan apakah sinyal yang diterima oleh receiver merupakan sinyal yang dipantulkan dari target ataukah sinyal yang hanya memuat noise dan clutter. Biasanya, sinyal-sinyal yang diterima receiver dibandingkan dengan threshold. Jika kuat sinyal melebihi threshold, maka proses deteksi menyatakan bahwa sinyal memuat sinyal target. Jika sebaliknya, maka proses deteksi menyatakan bahwa sinyal yang sampai ke receiver hanya merupakan noise atau clutter. Dengan prinsip deteksi seperti ini, maka ada empat kemungkinan hasil deteksi, sebagaimana dirangkum pada Tabel 1: i) target memang ada dan proses deteksi menyatakan ada, maka hasil deteksi adalah benar, ii) target tidak ada dan proses deteksi menyatakan tidak ada, maka hasil deteksi adalah benar, iii) target ada tetapi proses deteksi menyatakan tidak ada, maka hasil deteksi adalah salah, iv) target tidak ada tetapi proses deteksi menyatakan ada, maka hasil ini adalah salah. Kasus (iv) biasanya diistilahkan sebagai false alarm.

Tabel 1. Kemungkinan Hasil Deteksi

\begin{tabular}{|c|c|c|}
\hline Target & Deteksi & Hasil \\
\hline Tidak ada & Tidak & Benar \\
\hline Ada & Ya & Benar \\
\hline Ada & Tidak & Salah \\
\hline Tidak ada & Ya & Salah (false alarm $)$ \\
\hline
\end{tabular}

Threshold dan peluang deteksi muncul dalam bentuk yang cukup sulit dihitung, karena biasanya dinyatakan dalam bentuk integral lipat dua atau tiga dari fungsi-fungsi Bessel dengan batas-batas tak hingga. Ovarlez dan Immanuelle, telah merumuskan masalah ini secara sistematis[7] dan sebagian di antaranya akan dituliskan kembali pada bagian dua dalam paper ini. Di sini akan dapat dilihat peranan teknik aproksimasi Padé yang memberikan alternatif cara penghitungan thereshold dan peluang deteksi yang lebih mudah namun tetap akurat.

\section{Beberapa Relasi pada Deteksi Radar}

Misalkan $\boldsymbol{s}$ adalah sinyal target, $\boldsymbol{n}$ thermal noise dan $c$ clutter, semuanya dinyatakan dalam bilangan kompleks. Proses deteksi dapat dipandang sebagai pengujian hipotesis statistik: 


$$
\begin{aligned}
& H_{0}: \boldsymbol{y}=\boldsymbol{c}+\boldsymbol{n} \\
& H_{1}: \boldsymbol{y}=\mathbf{s}+\boldsymbol{c}+\boldsymbol{n} .
\end{aligned}
$$

Misalkan $f_{H 0}(r)$ menyatakan fungsi densitas dari $|\boldsymbol{c}+\boldsymbol{n}|, f_{H 1}(r)$ menyatakan fungsi densitas dari $|\boldsymbol{s}+\boldsymbol{c}+n|$, dan $\theta$ menyatakan threshold. Maka peluang terjadinya false alarm $P_{f a}$ dinyatakan oleh:

$$
P_{f a}=\int_{\theta}^{\infty} f_{H 0}(r) d r
$$

dan peluang deteksinya adalah:

$$
P_{d}=\int_{\theta}^{\infty} f_{H 1}(r) d r
$$

Dalam koordinat polar, kita dapat menuliskan sinyal kompleks:

$$
u+i v=r e^{i \phi}
$$

dengan $r$ adalah selubung sinyal dan $\phi$ adalah fasa. Nilai-nilai $r$ dan $\phi$ saling bebas dan $\phi$ diasumsikan berdistribusi seragam $[0,2 \pi]$. Karena itu, fungsi densitas bivariatnya:

$$
f_{u, v}(u, v)=f_{u, v}(r \cos \phi, r \sin \phi)=\frac{f_{r, \phi}(r, \phi)}{r}=\frac{f_{r}(r)}{2 \pi r}
$$

Fungsi karakteristik dari fungsi densitas bivariat di atas adalah:

$$
C\left(t_{1}, t_{2}\right)=\int_{-\infty-\infty}^{\infty} \int^{\infty} e^{i\left(t_{1} u+t_{2} v\right)} f_{u, v}(u, v) d u d v
$$

Jika ditranformasi ke koordinat polar, dengan:

maka:

$$
\begin{array}{ll}
t_{1}=\rho \cos \theta & t_{2}=\rho \sin \theta \\
u=r \cos \phi & v=r \sin \phi
\end{array}
$$

$$
C(\rho, \theta)=\int_{0}^{\infty} \int_{0}^{2 \pi} e^{i \rho r \cos (\phi-\theta) \frac{f_{r}(r)}{2 \pi r} r d \phi d r}=\int_{0}^{\infty} f_{r}(r) J_{0}(\rho r) d r
$$

dengan $J_{0}(\bullet)$ menyatakan fungsi Bessel orde nol. Karena fungsi karakteristik di atas tidak bergantung pada $\theta$, maka dapat dituliskan sebagai:

$$
C(\rho)=\int_{0}^{\infty} f_{r}(r) J_{0}(\rho r) d r
$$

dan dikenal sebagai fungsi karakteristik radial. Lebih jauh, bentuk (5) menyatakan transformasi Hankel orde nol dari fungsi $f_{r}(r)$. Dengan menerapkan invers transformasi Hankel dapat diperoleh:

$$
f_{r}(r)=\int_{0}^{\infty} \operatorname{\rho r} C(\rho) J_{0}(\rho r) d \rho
$$

Untuk kasus sinyal target dengan selubung konstan, misalnya $A$, fungsi densitasnya diberikan oleh:

$$
f_{r}(r)=\delta(r-A)
$$

Dengan menggunakan sifat fungsi delta Dirac, maka fungsi karakteristik radialnya diperoleh yaitu

$$
C_{s}(\rho)=J_{0}(\rho A)
$$

Karena fungsi karakteristik radial:

maka:

$$
\begin{aligned}
f_{H_{1}}(r \mid A) & =\int_{0}^{\infty} \rho r C_{s}(\rho) C_{H_{0}}(\rho) J_{0}(\rho r) d \rho \\
& =\int_{0}^{\infty} \rho r J_{0}(\rho A) C_{H_{0}}(\rho) J_{0}(\rho r) d \rho
\end{aligned}
$$

Untuk kasus envelope sinyal target berfluktuasi dengan fungsi densitas $f\left(A \mid A_{0}\right)$, di mana $A_{0}$ adalah mean dari selubung $A$, maka

$$
f_{H_{1}}\left(r \mid A_{0}\right)=\int_{0}^{\infty} f_{H_{1}}(r \mid A) f\left(A \mid A_{0}\right) d A
$$

Peluang deteksi, baik untuk (9) maupun (10), secara umum sulit dihitung. Karena itu, peluang deteksi akan dihitung dengan menerapkan teknik aproksimasi. Teknik aproksimasi yang akan digunakan di sini adalah teknik aproksimasi Padé.

\section{Aproksimasi Padé}

Misalkan $h(u)$ adalah fungsi dengan deret pangkat di sekitar $u=0$, dapat dituliskan sebagai:

$$
h(u)=\sum_{n=0}^{\infty} c_{n} u^{n}
$$

Aproksimasi Padé dari fungsi $h(u)$ dengan orde $[L / M]$ adalah suatu fungsi rasional:

$$
P^{[L / M]}(u)=\frac{\sum_{n=0}^{L} a_{n} u^{n}}{\sum_{n=0}^{M} b_{n} u^{n}}=\sum_{n=0}^{L+M} c_{n} u^{n}+o\left(u^{L+M+1}\right)
$$

untuk $u$ di sekitar 0 . Tanpa mengurangi keumuman, biasanya dipilih $b_{0}=1$. Nilai-nilai $a_{0}, a_{1}, \ldots, a_{L}$ dan $b_{1}, b_{2}, \ldots, b_{M}$ dapat diperoleh dari persamaan (12) dengan cara menyamakan koefisien dari pangkat $u$ yang sama:

$$
\sum_{n=0}^{L} a_{n} u^{n}=\left(1+\sum_{n=1}^{M} b_{n} u^{n}\right) \sum_{n=0}^{L+M} c_{n} u^{n}
$$

Dengan cara ini diperoleh:

$$
\sum_{n=0}^{M} b_{n} c_{L-n+j}=-c_{L+j}, 1 \leq j \leq M
$$

Persamaan-persamaan pada (13) membentuk $M$ persamaan linear dengan $M$ variabel yang tak diketahui. Sistem persamaan linear tersebut dapat dituliskan dalam bentuk perkalian matriks

$$
\left[\begin{array}{cccc}
c_{L-M+1} & c_{L-M+2} & \cdots & c_{L} \\
\vdots & \vdots & \vdots & \vdots \\
c_{L-M+k} & c_{L-M+k+1} & \cdots & c_{L+k-1} \\
\vdots & \vdots & \vdots & \vdots \\
c_{L} & c_{L+1} & \cdots & c_{L+M-1}
\end{array}\right]\left[\begin{array}{c}
b_{M} \\
\vdots \\
b_{k} \\
\vdots \\
b_{1}
\end{array}\right]=-\left[\begin{array}{c}
c_{L+1} \\
\vdots \\
c_{L+k} \\
\vdots \\
c_{L+M}
\end{array}\right]
$$

Matriks yang berada di kiri dikenal sebagai matriks Hankel. Jika matriks Hankelnya mempunyai rank penuh, maka nilai-nilai $b_{1}, b_{2}, \ldots, b_{M}$ dapat ditentukan secara tunggal. Selanjutnya nilai-nilai $a_{1}, a_{2}, \ldots, a_{L}$ dapat diperoleh dari:

$$
a_{j}=c_{j}+\sum_{i=1}^{\min (M, j)} b_{i} c_{j-i}, 0 \leq j \leq L
$$


Khusus untuk fungsi-fungsi Stieltjes, yaitu fungsi-fungsi yang dapat dituliskan dalam bentuk

$$
S(u)=\int_{0}^{\infty} \frac{d \psi(z)}{1+z u}
$$

dengan $\psi(\mathrm{z})$ adalah fungsi yang terbatas dan tak turun, aproksimasi Padé diagonal $P^{[M / M]}(u)$ dan subdiagonal $P^{[M-1 / M]}(u)$ akan konvergen untuk $M \rightarrow \infty[1]$. Walaupun hasil ini tidak dijamin berlaku untuk sembarang fungsi, namun hasil ini memotivasi penggunaan aproksimasi subdiagonal $P^{[M-l / M]}(u)$ dalam tulisan ini. Selain itu, bentuk subdiagonal $P^{[M-l / M]}(u)$ akan memudahkan ketika bekerja dengan invers transformasi Laplace dalam melakukan aproksimasi fungsi densitas.

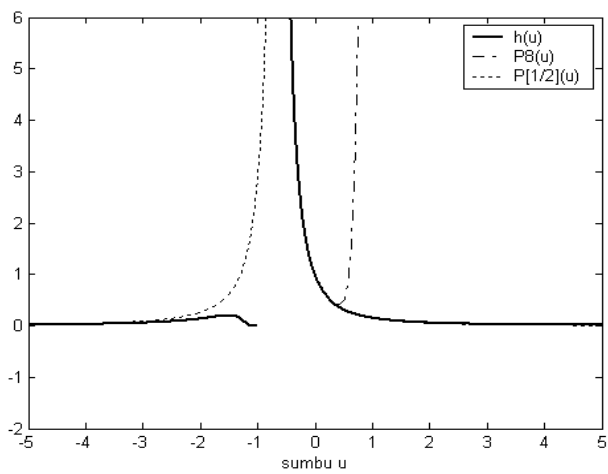

Gambar 1. Grafik $h(u), P^{8}(u)$ dan $P^{[1 / 2]}(u)$

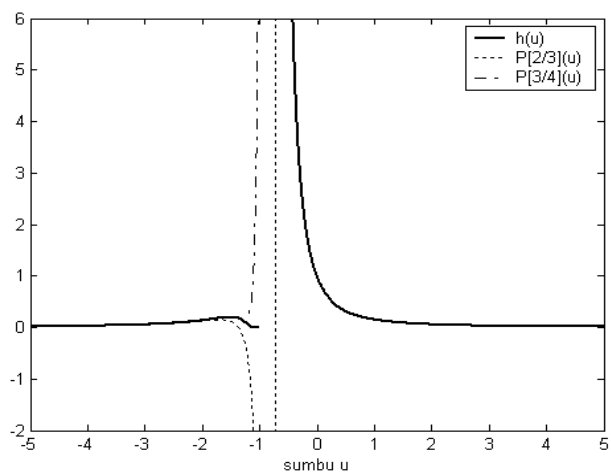

Gambar 2. Grafik $h(u), P^{[2 / 3]}(u)$ dan $P^{[3 / 4]}(u)$

Dari Gambar 1 terlihat bahwa untuk $|u|$ yang besar, aproksimasi Padé memberikan hasil yang cukup baik. Ini berbeda dengan aproksimasi polinom Taylor yang justru divergen di sana. Sementara itu, juga dapat dilihat bahwa $h(u)$ memiliki singularitas di $u=-1$. Dengan bertambahnya $M$, aproksimasi Padé akan memberikan hasil yang lebih baik di sekitar $u=-1$ (lihat Gambar 2). Sementara itu, polinom Taylor tidak dapat diandalkan di sekitar singularitas, karena polinom tidak mempunyai singularitas.

\section{Contoh 1.}

Misalkan ingin diaproksimasikan fungsi:

$$
h(u)=\frac{e^{(-u / 1+u)}}{(1+u)^{2}}
$$

Dari ekspansi Taylor di sekitar $u=0$ diperoleh:

$$
\begin{aligned}
h(u)= & 1-3 u+\frac{13}{2} u^{2}-\frac{73}{6} u^{3}+\frac{167}{8} u^{4}-\frac{4051}{120} u^{5} \\
& +\frac{37633}{720} u^{6}-\frac{43817}{560} u^{7}+\frac{4596553}{40320} u^{8}+o\left(u^{9}\right)
\end{aligned}
$$

sehingga polinom Taylor orde 8 untuk fungsi $h(u)$ adalah:

$$
\begin{aligned}
P^{8}(u)= & 1-3 u+\frac{13}{2} u^{2}-\frac{73}{6} u^{3}+\frac{167}{8} u^{4}-\frac{4051}{120} u^{5} \\
& +\frac{37633}{720} u^{6}-\frac{43817}{560} u^{7}+\frac{4596553}{40320} u^{8}
\end{aligned}
$$

Untuk $M=2,3$ dan 4, aproksimasi Padé subdiagonalnya adalah:

$$
\begin{aligned}
& P^{[1 / 2]}(u)=\frac{1-\frac{1}{15} u}{1+\frac{44}{15} u+\frac{23}{10} u^{2}} \\
& P^{[2 / 3]}(u)=\frac{1+\frac{36}{49} u+\frac{1}{980} u^{2}}{1+\frac{183}{49} u+\frac{4611}{980} u^{2}+\frac{5899}{2940} u^{3}} \\
& P^{[3 / 4]}(u)=\frac{1+\frac{1137}{685} u+\frac{1333}{1918} u^{2}-\frac{1}{143850}}{1+\frac{3192}{685} u+\frac{39197}{4795} u^{2}+\frac{460412}{71925} u^{3}+\frac{362331}{191800} u^{4}}
\end{aligned}
$$

\section{Aproksimasi Padé untuk Fungsi Densitas}

Selanjutnya, kita akan melihat bagaimana teknik aproksimasi Padé dapat digunakan untuk mengaproksimasi fungsi densitas dari suatu variable random non-negatif $X$, bila momen-momennya diketahui. Teknik ini pertama kali diperkenalkan oleh Amindavar pada tahun 1994 [1].

Misalkan $m(u)$ adalah fungsi pembangkit momen dari suatu variabel random non negatif $X$ dan $f(x)$ adalah fungsi densitas dari $X$. Maka $m(u)$ didefinisikan sebagai:

$$
m(u)=\int_{0}^{\infty} e^{-u x} f(x) d x
$$

yang merupakan transformasi Laplace dari $f(x)$.

Misalkan momen-momen $E[X], E\left[X^{2}\right], \ldots$, $E\left[X^{N}\right]$ diketahui (nilai-nilainya dapat ditaksir cukup akurat), maka $m(u)$ dapat dituliskan sebagai deret pangkat dari momen-momennya:

$$
m(u)=\sum_{n=0}^{\infty} E\left[X^{n}\right] \frac{(-u)^{n}}{n !}
$$

Oleh karena itu, $m(u)$ dapat diaproksimasi dengan deret pangkat:

$$
m(u) \approx \sum_{n=0}^{N} E\left[X^{n}\right] \frac{(-u)^{n}}{n !}
$$

Berdasarkan (15), aproksimasi Padé subdiagonal dapat dikonstruksikan:

$$
P^{[M-1 / M]}(u)=\frac{\sum_{n=0}^{M-1} a_{n} u^{n}}{1+\sum_{n=1}^{M} b_{n} u^{n}}
$$

Bila diterapkan invers transformasi Laplace, maka diperoleh aproksimasi Padé untuk fungsi densitas:

Misalkan:

$$
f(x) \approx \mathcal{L}^{-1}\left\{P^{[M-1 / M]}(u)\right\}=f^{[M-1 / M]}(x)
$$

$$
P^{[M-1 / M]}(u)=\sum_{k=1}^{M} \frac{\lambda_{k}}{u-\alpha_{k}}
$$

maka secara eksplisit dapat dituliskan: 


$$
f^{[M-1 / M]}(x)=\sum_{k=1}^{M} \lambda_{k} e^{\alpha_{k} x}
$$

Jika $m(u)$ dapat diaproksimasikan cukup baik untuk $u \rightarrow 0$, maka hasil aproksimasi untuk $f(x)$ yang diperoleh akan cukup baik untuk $x \rightarrow \infty$. Dan sebaliknya, jika $m(u)$ dapat diaproksimasikan cukup baik untuk $u \rightarrow \infty$, maka hasil aproksimasi untuk $f(x)$ yang diperoleh akan cukup baik untuk $x \rightarrow 0$. Hal ini dapat didasarkan pada teorema nilai awal dan nilai akhir transformasi Laplace [5].

\section{Contoh 2.}

Pada Contoh 1, dilakukan aproksimasi Padé terhadap fungsi

$$
h(u)=\frac{e^{(-u / 1+u)}}{(1+u)^{2}}
$$

dan aproksimasi Padé orde [1/2] untuk $h(u)$ adalah

$$
h(u) \approx \sum_{k=1}^{2} \frac{\lambda_{k}}{u-\alpha_{k}}
$$

dengan

$$
\begin{aligned}
& \lambda_{1}=-0.01449275362+i 1.350889900 \\
& \lambda_{2}=-0.01449275362-i 1.350889900 \\
& \alpha_{1}=-0.6376811594-i 0.167765722 \\
& \alpha_{2}=-0.6376811594+i 0.167765722
\end{aligned}
$$

Fungsi $h(u)$ di atas merupakan fungsi pembangkit momen dari fungsi densitas $f(x)$, yaitu:

$$
f(x)=\sqrt{x} e^{-(1+x)} I_{1}(2 \sqrt{x})
$$

dengan $I_{1}(x)$ adalah fungsi Bessel termodifikasi orde-1. Bila dilakukan invers transformasi Laplace terhadap $P^{[1 / 2]}(u)$, maka diperoleh aproksimasi Padé untuk $f(x)$ :

$$
f^{[1 / 2]}(x)=-\frac{2}{69} e^{-\frac{44}{69} x} \cos \left(\frac{\sqrt{134}}{69} x\right)+\frac{1079}{4623} \sqrt{134} e^{-\frac{44}{69} x} \sin \left(\frac{\sqrt{134}}{69} x\right)
$$

Bila diplot, diperoleh grafiknya pada Gambar 3.

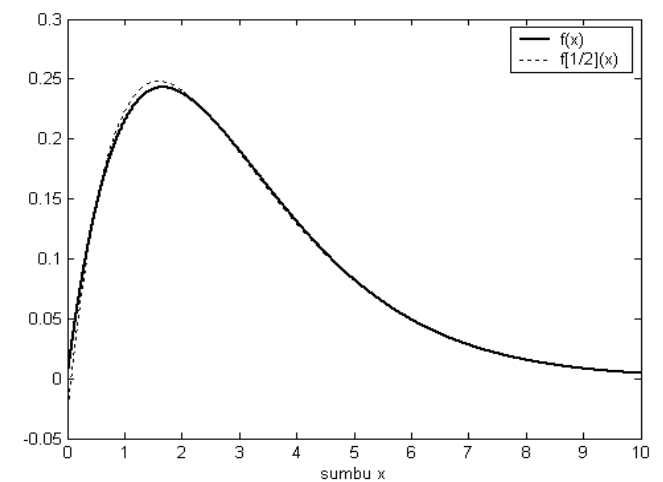

Gambar 3. Grafik $f(x)$ dan $f^{[1 / 2]}(x)$

Terlihat bahwa $f^{[1 / 2]}(x)$ mengaproksimasi $f(x)$ cukup baik untuk $x$ yang besar.

\section{Penerapan}

Sekarang, kita dilihat bagaimana teknik aproksimasi Padé dapat diterapkan untuk menghitung (9) dan (10) secara lebih mudah tetapi cukup akurat. Misalkan dengan menggunakan aproksimasi Padé, $f_{H O}(r)$ dapat diaproksimasikan:

$$
f_{H_{0}}(r) \approx \sum_{k=1}^{M} \lambda_{k} e^{\alpha_{k} r}
$$

maka:

$$
P_{f a}=\int_{\theta}^{\infty} \sum_{k=1}^{M} \lambda_{k} e^{\alpha_{k} r} d r=-\sum_{k=1}^{M} \frac{\lambda_{k}}{\alpha_{k}} e^{\alpha_{k} \theta}
$$

dan:

$$
\begin{aligned}
f_{H_{1}}(r \mid A) & \approx \int_{0}^{\infty} \rho r J_{0}(\rho A) \int_{0}^{\infty} \sum_{k=1}^{M} \lambda_{k} e^{\alpha_{k} r^{\prime}} J_{0}\left(\rho r^{\prime}\right) d r^{\prime} J_{0}(\rho r) d \rho \\
& =\int_{0}^{\infty} \rho r J_{0}(\rho A) \sum_{k=1}^{M} \frac{\lambda_{k}}{\sqrt{\rho^{2}+\alpha_{k}^{2}}} J_{0}(\rho r) d \rho
\end{aligned}
$$

Karena:

$$
\int_{0}^{\theta} r J_{0}(\rho r) d r=\frac{\theta}{\rho} J_{1}(\rho \theta)
$$

maka:

$$
\begin{aligned}
P_{d} & \approx 1-\int_{0}^{\theta} \int_{0}^{\infty} \rho r J_{0}(\rho A) \sum_{k=1}^{\infty} \frac{\lambda_{k}}{\sqrt{\rho^{2}+\alpha_{k}^{2}}} J_{0}(\rho r) d \rho d r \\
& =1-\int_{0}^{\infty} \sum_{k=1}^{M} \lambda_{k} \theta \frac{J_{0}(\rho A) J_{1}(\rho \theta)}{\sqrt{\rho^{2}+\alpha_{k}^{2}}} d \rho
\end{aligned}
$$

Sekarang dilihat untuk kasus dengan selubung sinyal target berfluktuasi. Misalkan dengan aproksimasi Padé:

$$
f\left(A \mid A_{0}\right) \approx \sum_{i=1}^{N} \gamma_{i} e^{\delta_{i} A}
$$

Maka persamaan (10) menjadi:

$$
\begin{aligned}
f_{H_{1}}\left(r \mid A_{0}\right) & =\int_{0}^{\infty} f_{H_{1}}(r \mid A) \sum_{i=1}^{N} \gamma_{i} e^{\delta_{i} A} d A \\
& =\int_{0}^{\infty} \sum_{k=1}^{M} \sum_{i=1}^{N} \lambda_{k} \gamma_{i} \frac{\rho r J_{0}(\rho r)}{\sqrt{\left(\rho^{2}+\alpha_{k}^{2}\right)\left(\rho^{2}+\delta_{i}^{2}\right)}} d \rho
\end{aligned}
$$

Sehingga peluang deteksinya dapat dihitung sebagai:

$$
P_{d} \approx 1-\int_{0}^{\infty} \sum_{k=1}^{M} \sum_{i=1}^{N} \frac{\lambda_{k} \gamma_{i} \theta J_{1}(\rho \theta)}{\sqrt{\left(\rho^{2}+\alpha_{k}^{2}\right)\left(\rho^{2}+\delta_{i}^{2}\right)}} d \rho
$$

\section{Contoh 3.}

Misalkan $\boldsymbol{c}=0, \boldsymbol{n}=x+i y$ derau Gaussian kompleks dengan variansi $\sigma^{2}$ dan $s$ sinyal target dengan selubung konstan sebesar $A$, maka:

$$
f_{x, y}(x, y)=\frac{1}{2 \pi \sigma^{2}} e^{-\frac{x^{2}+y^{2}}{2 \sigma^{2}}}
$$

atau

$$
f_{H_{0}}\left(r_{0}\right)=\frac{r_{0}}{\sigma^{2}} e^{-\frac{r_{0}^{2}}{2 \sigma^{2}}}
$$

Fungsi karakteristik radialnya dapat diperoleh, yaitu:

$$
C_{H_{0}}(\rho)=e^{-1 / 2 \rho^{2} \sigma^{2}}
$$

Sehingga

$$
\begin{aligned}
f_{H_{1}}(r \mid A) & =\int_{0}^{\infty} \rho r J_{0}(\rho A) C_{H_{0}}(\rho) J_{0}(\rho r) d \rho \\
& =\frac{r}{\sigma^{2}} \exp \left(-\frac{A^{2}+r^{2}}{2 \sigma^{2}}\right) I_{0}\left(\frac{r A}{\sigma^{2}}\right)
\end{aligned}
$$


yang dikenal sebagai fungsi densitas dari distribusi Rice Nakagami (Rician). Untuk $\sigma=1$ dan $P_{f a}=10^{-6}$ diperoleh nilai threshold sebesar $\theta=5.256521769$. Sekarang akan dibandingkan hasil tersebut dengan hasil aproksimasi Padé. Aproksimasi Padé subdiagonal untuk $f_{H O}(r)$ dengan $M=6$ adalah:

$$
f_{H 0}^{[5 / 6]}(r)=\sum_{k=1}^{6} \lambda_{k} e^{\alpha_{k} r}
$$

dengan:

$$
\begin{aligned}
& \lambda_{1}=4.860733459+i 86.71745609 \\
& \lambda_{2}=4.860733459-i 86.71745609 \\
& \lambda_{3}=-5.732893022-i 33.91473496 \\
& \lambda_{4}=-5.732893022+i 33.91473496 \\
& \lambda_{5}=0.8690466039+i 3.621773010 \\
& \lambda_{6}=0.8690466039-i 3.621773010 \\
& \alpha_{1}=-2.996491792-i 0.4409598137 \\
& \alpha_{2}=-2.996491792+i 0.4409598137 \\
& \alpha_{3}=-2.910045029-i 1.364542841 \\
& \alpha_{4}=-2.910045029+i 1.364542841 \\
& \alpha_{5}=-2.718943745-i 2.457150851 \\
& \alpha_{6}=-2.718943745+i 2.457150851
\end{aligned}
$$

\begin{tabular}{|c|c|c|}
\hline$A$ & Eksak & Padé \\
\hline (0 & $1.7693 \times 10^{-6}$ & $2.599 \times 10^{-7}$ \\
\hline 1 & $1.8897 \times 10^{-6}$ & $1.6743 \times 10^{-6}$ \\
\hline 2 & $6.4558 \times 10^{-6}$ & $6.2417 \times 10^{-6}$ \\
\hline 3 & $2.79682 \times 10^{-5}$ & $2.77538 \times 10^{-5}$ \\
\hline 4 & $1.264633 \times 10^{-4}$ & $1.262495 \times 10^{-4}$ \\
\hline 5 & $5.861756 \times 10^{-4}$ & $5.859642 \times 10^{-4}$ \\
\hline 6 & $2.7353766 \times 10^{-3}$ & $2.7351757 \times 10^{-3}$ \\
\hline 7 & $1.26416323 \times 10^{-2}$ & $1.26414789 \times 10^{-2}$ \\
\hline 8 & $5.67050829 \times 10^{-2}$ & $5.67051325 \times 10^{-2}$ \\
\hline 9 & 0.2357504183 & 0.2356365854 \\
\hline 10 & 0.6984959301 & 0.6984971118 \\
\hline 11 & 0.9317231882 & 0.9317228340 \\
\hline 12 & 0.9861295043 & 0.9861288196 \\
\hline 13 & 0.9973082999 & 0.9973076309 \\
\hline 14 & 0.9994904713 & 0.9994899077 \\
\hline
\end{tabular}

memberikan nilai threshold sebesar 5.288753651. Di Tabel 2 dan Gambar 4 diperbandingkan peluang deteksi hasil aproksimasi dan eksak untuk $P_{f a}=10^{-6}$.

Tabel 2. Nilai $P_{d}$ pada Derau Gaussian Kompleks

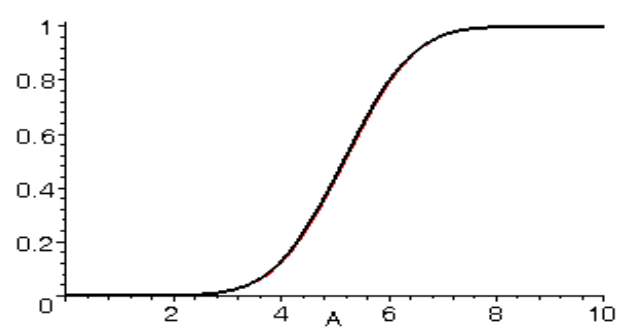

Gambar 4. Grafik $P_{d}$ terhadap $A$

dengan Derau Gaussian Kompleks

(nilai eksak dan hasil aproksimasi Padé berhimpit)

\section{Contoh 4.}

Misalkan $\boldsymbol{n}=0$ (tanpa derau), dan selubung clutter berdistribusi $K$ dengan fungsi densitas:

$$
f_{H_{0}}(r)=\frac{2 b(b r / 2)^{v+1}}{\Gamma(v+1)} K_{v}(b r)
$$

Khususnya untuk fungsi ini, fungsi karakteristik radialnya adalah:

$$
C_{H_{0}}(\rho)=b^{2 v+2}\left(\rho^{2}+v^{2}\right)^{-v-1}
$$

Untuk $v=0.5$ dan $b=\sqrt{ } 3$, aproksimasi Padé [1/2] untuk $f_{H O}(r)$ adalah:

$$
f_{H_{0}}^{[1 / 2]}(r)=\sum_{k=1}^{2} \lambda_{k} e^{\alpha_{k} r}
$$

dengan:

$$
\begin{array}{ll}
\lambda_{1}=-18140.80915 & \lambda_{2}=18140.80915 \\
\alpha_{1}=-1.732133502 & \alpha_{2}=-1.731968129
\end{array}
$$

Untuk $P_{f a}=10^{-6}$, diperoleh secara numerik nilai threshold $\hat{\theta}=9.635064233$ dan hasil nilai eksaknya $\theta=9.635064233$, dengan peluang deteksi seperti pada Tabel 3 dan Gambar 5.

Tabel 3. Perbandingan $P_{d}$ Tanpa Derau

\begin{tabular}{|c|c|c|}
\hline$A$ & Eksak & Padé \\
\hline 0 & $9.999999987 \times 1^{-7}$ & $7.4934 \times 10^{-6}$ \\
\hline 1 & $2.49066762 \times 10^{-5}$ & $2.18032 \times 10^{-5}$ \\
\hline 2 & $9.4806735 \times 1^{-4}$ & $8.473732 \times 1^{-4}$ \\
\hline 3 & $1.654477412 \times 10^{-2}$ & $1.524392 \times 10^{-2}$ \\
\hline 4 & $\mathbf{0 . 1 2 5 6 9 7 7 0 0 6}$ & $\mathbf{0 . 1 1 9 0 9 8 8 5 1 7}$ \\
\hline 5 & $\mathbf{0 . 4 3 7 0 8 0 6 6 3 0}$ & $\mathbf{0 . 4 2 4 2 7 8 7 7 5 9}$ \\
\hline 6 & $\mathbf{0 . 7 9 7 5 5 8 2 4 0 8}$ & $\mathbf{0 . 7 8 8 2 7 7 5 2 2 0}$ \\
\hline 7 & $\mathbf{0 . 9 6 6 0 7 5 9 7 7 2}$ & $\mathbf{0 . 9 6 3 5 5 6 9 7 3 5}$ \\
\hline 8 & $\mathbf{0 . 9 9 7 6 0 1 3 5 9 6}$ & $\mathbf{0 . 9 9 7 3 4 6 0 5 8 6}$ \\
\hline 9 & $\mathbf{0 . 9 9 9 9 3 2 0 6 6 7}$ & $\mathbf{0 . 9 9 9 9 2 2 7 5 8 3}$ \\
\hline 10 & $\mathbf{0 . 9 9 9 9 9 9 2 5 1 0}$ & $\mathbf{0 . 9 9 9 9 9 9 1 7 0 0}$ \\
\hline
\end{tabular}

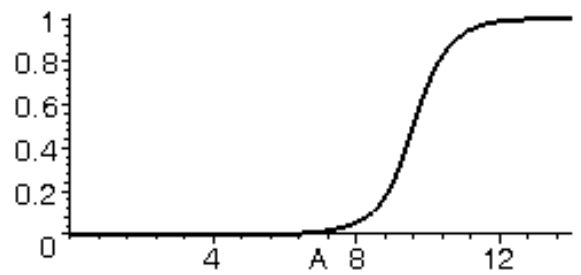

Gambar 5. Grafik $P_{d}$ terhadap $A$ Tanpa Derau (nilai eksak dan hasil aproksimasi Padé berhimpit)

\section{Contoh 5.}

Misalkan $\boldsymbol{n}$ derau Gaussian kompleks dengan variansi $\sigma^{2}$ dan $c$ clutter dengan selubung clutter berdistribusi $K$ seperti pada Contoh 4, maka:

$$
P_{f a}=\int_{\theta}^{\infty} f_{H_{0}}(r) d r
$$

Misalkan dengan menggunakan aproksimasi Padé:

$$
f_{n}(r) \approx \sum_{j=1}^{N} \gamma_{j} e^{-\alpha_{j} r}
$$

dan

$$
f_{c}(r) \approx \sum_{k=1}^{M} \lambda_{k} e^{-\delta_{k} r}
$$

maka:

$$
\begin{aligned}
f_{H_{0}}(r) & =\int_{0}^{\infty} \rho r C_{c}(\rho) C_{n}(\rho) J_{0}(\rho r) d \rho \\
& \approx \int_{0}^{\infty} \rho r \sum_{k=1}^{M} \sum_{j=1}^{N} \frac{\lambda_{k}}{\sqrt{\rho^{2}+\delta_{k}^{2}}} \frac{\gamma_{j}}{\sqrt{\rho^{2}+\alpha_{j}^{2}}} J_{0}(\rho r) d \rho
\end{aligned}
$$

sehingga:

$$
P_{f a}=\int_{\theta}^{\infty} f_{H_{0}}(r) d r \approx \int_{0}^{\infty} \theta \sum_{k=1}^{M} \sum_{j=1}^{N} \frac{\lambda_{k}}{\sqrt{\rho^{2}+\delta_{k}^{2}}} \frac{\gamma_{j}}{\sqrt{\rho^{2}+\alpha_{j}^{2}}} J_{1}(\rho \theta) d \rho
$$


Dengan memanfaatkan hasil pada Contoh 3 dan Contoh 4, secara numerik dapat diperoleh nilai threshold untuk $P_{f a}=10^{-6}$ sebesar $\hat{\theta}=10.485$. Dengan cara eksak, yakni dengan menyelesaikan secara langsung persamaannya:

$$
\begin{aligned}
P_{f a} & =\int_{\theta}^{\infty} f_{H_{0}}(r) d r=1-\int_{0}^{\theta} f_{H_{0}}(r) d r \\
& =1-\int_{0}^{\theta} \int_{0}^{\infty} \rho r C_{c}(\rho) C_{n}(\rho) J_{0}(\rho r) d \rho d r \\
& =1-\int_{0}^{\infty} C_{c}(\rho) C_{n}(\rho) J_{1}(\rho \theta) d \rho
\end{aligned}
$$

diperoleh nilai threshold sebesar $\theta=10.4985$. Selanjutnya kita akan menghitung peluang deteksi:

$$
f_{H_{1}}(r) \approx \int_{0}^{\infty} \rho r J_{0}(\rho A) \sum_{k=1}^{M} \sum_{j=1}^{N} \frac{\lambda_{k}}{\sqrt{\rho^{2}+\delta_{k}^{2}}} \frac{\gamma_{j}}{\sqrt{\rho^{2}+\alpha_{j}^{2}}} J_{0}(\rho r) d \rho
$$

sehingga:

$$
\begin{aligned}
P_{d} & =\int_{\theta}^{\infty} f_{H_{1}}(r) d r \\
& \approx \int_{\theta}^{\infty} \int_{0}^{\infty} \rho r J_{0}(\rho A) \sum_{k=1}^{M} \sum_{j=1}^{N} \frac{\lambda_{k}}{\sqrt{\rho^{2}+\delta_{k}^{2}}} \frac{\gamma_{j}}{\sqrt{\rho^{2}+\alpha_{j}^{2}}} J_{0}(\rho r) d \rho d r \\
& =1-\int_{0}^{\infty} \theta J_{0}(\rho A) \sum_{k=1}^{M} \sum_{j=1}^{N} \frac{\lambda_{k}}{\sqrt{\rho^{2}+\delta_{k}^{2}}} \frac{\gamma_{j}}{\sqrt{\rho^{2}+\alpha_{j}^{2}}} J_{1}(\rho \theta) d \rho
\end{aligned}
$$

\begin{tabular}{|c|c|c|}
\hline$A$ & Eksak & Padé \\
\hline $\mathbf{0}$ & $1.0004 \times 10^{-6}$ & $9.632 \times 10^{-7}$ \\
\hline 1 & $1.8364 \times 10^{-6}$ & $1.7326 \times 10^{-6}$ \\
\hline 2 & $6.899 \times 10^{-6}$ & $6.2179 \times 10^{-6}$ \\
\hline 3 & $2.74338 \times 10^{-5}$ & $2.73021 \times 10^{-5}$ \\
\hline 4 & $1.228537 \times 10^{-4}$ & $1.246297 \times 10^{-4}$ \\
\hline 5 & $5.609354 \times 10^{-4}$ & $5.720422 \times 10^{-4}$ \\
\hline 6 & $2.5530512 \times 10^{-3}$ & $2.6058410 \times 10^{-3}$ \\
\hline 7 & $1.12731293 \times 10^{-2}$ & $1.14999611 \times 10^{-2}$ \\
\hline 8 & $4.57025648 \times 10^{-2}$ & $4.65379110 \times 10^{-2}$ \\
\hline 9 & 0.1535193576 & 0.1557861598 \\
\hline 10 & 0.3813551616 & 0.3851793916 \\
\hline 11 & 0.6690410039 & 0.6726683279 \\
\hline 12 & 0.8769541551 & 0.8788884142 \\
\hline 13 & 0.9665751278 & 0.9672165426 \\
\hline 14 & 0.9925511631 & 0.9927074861 \\
\hline 15 & 0.9984913647 & 0.9985238205 \\
\hline 16 & 0.9997075288 & 0.9997134737 \\
\hline 17 & 0.9999446177 & 0.9999453709 \\
\hline
\end{tabular}

Hasil perhitungan peluang deteksi dengan derau dan clutter diperlihatkan pada Tabel 4 dan Gambar 5.

Tabel 4. Nilai Pd dengan Derau dan Clutter

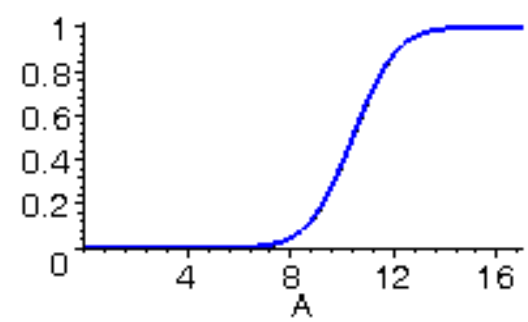

Gambar 5. Grafik $P_{d}$ terhadap $A$ dengan Derau dan Clutter

(nilai eksak dan hasil aproksimasi Padé berhimpit)

\section{Kesimpulan}

Dari uraian diatas, dapat dicatat beberapa kesimpulan. Aproksimasi Padé merupakan alternatif untuk memperoleh hasil perhitungan yang lebih baik jika aproksimasi dengan polinom Taylor tidak memuaskan. Aproksimasi Padé subdiagonal dapat dimanfaatkan untuk mempermudah perhitungan dalam mendapatkan invers transformasi Laplace dari suatu fungsi, bila invers transformasi Laplace secara langsung sulit diterapkan. Bila beberapa momen dari suatu variable random $X$ diketahui (dapat ditaksir cukup akurat), maka fungsi densitasnya dapat diaproksimasi dengan memanfaatkan aproksimasi Padé subdiagonal dan menerapkan invers transformasi Laplace. Hasil aproksimasi cukup baik untuk nilai $x$ yang cukup besar. Aproksimasi Padé memberikan alternatif perhitungan yang lebih mudah dalam menghitung threshold dan peluang deteksi pada analisis performansi deteksi radar.

\section{Daftar Pustaka:}

[1] Amindavar, H., and Ritcey, J. A. Padé Approximations of Probability Density Function, IEEE Trans, on Aerospace and Electronic System, Vol. 30 No. 2 April 1994 pp. 416-424.

[2] Amindavar, H., and Ritcey, J. A. Padé Approximations for Detectibility in K-clutter and Noise, IEEE Trans, on Aerospace and Electronic System. Vol. 30 No. 2 April 1994, pp. 425-434.

[3] Bateman, H., 1954, Tables of Integral Transforms, Vol 1. NewYork, McGraw-Hill Book Company, Inc.

[4] Cheney, E.W., 1966, Introduction to Approximation Theory. New York, McGraw-Hill Book Company, Inc.

[5] Dyke, P.P.G., 2000, An Introduction to Laplace Transform and Fourier Series, London. Springer Verlag.

[6] Edde, B., 1993, RADAR: Principles, Technology, Applications, New Jersey, Prentice-Hall International, Inc.

[7] Ovarlez, J.P and Immanuelle, J. New Methods of Radar Detection Performances Analysis. www.telecom.tuc.gr /paperdb /icassp99/PDF/ SCAN /IC991929.PDF .

[8] Sneddon, I., 1951, Fourier Transforms, New York, McGraw-Hill, Inc.

[9] Sullivan, J., Padé Approximation via The Continued Fraction Approach, American Journal of Physics. Vol. 46 No.5 May 1978 pp. 489-494.

[10] Watson, G.N., 1966, Theory of Bessel Functions, London, Cambridge University Press. 